\title{
Simultaneous Automated Determination of Glucose 6-Phosphate Dehydrogenase and 6-Phosphogluconate Dehydrogenase Activities in Whole Blood ${ }^{1}$ )
}

\author{
Andrea Mosca ${ }^{1}$, Renata Paleari ${ }^{1}$, Enrico Rosti ${ }^{2}$, Massimo Luzzana ${ }^{1}$, Susanna Barella ${ }^{3}$, Carla Sollaino ${ }^{3}$ and \\ Renzo Galanello ${ }^{3}$
}

1 Dipartimento di Scienze e Tecnologie Biomediche, Università degli Studi, Milano, Italy

2 I.T.B.A., CNR, Milano, Italy

${ }^{3}$ Ist. di Clinica e Biologia dell' Età Evolutiva, Università degli Studi, Cagliari, Italy

Summary: We report a potentiometric fully automated method for determining red cell glucose 6-phosphate dehydrogenase, 6-phosphogluconate dehydrogenase activities and the glucose 6-phosphate dehydrogenase/6-phosphogluconate dehydrogenase index using $25 \mu \mathrm{l}$ of whole blood. No sample pre-treatment (e. g., preparation of the haemolysate) is needed and the measurements are performed at $\mathrm{pH} 8.0$ and $37^{\circ} \mathrm{C}$ under the conditions recommended by the ICSH committee. The reproducibility was constantly good, with within-run CV of $1.0 \%$ (glucose 6-phosphate dehydrogenase) and 5.9\% (glucose 6-phosphate dehydrogenase/6-phosphogluconate dehydrogenase) for activities in glucose 6-phosphate dehydrogenase non-deficient adults, and of 2.3\% (glucose 6-phosphate dehydrogenase, G6PD) and 2.5\% (glucose 6-phosphate dehydrogenase/6-phosphogluconate dehydrogenase) for G6PD Mediterranean heterozygotes. Linearity was observed up to an activity of $2800 \mathrm{U} / \mathrm{l}$ of glucose 6-phosphate dehydrogenase. Results of glucose 6-phosphate dehydrogenase activity (U/l) in whole blood $(y)$ correlated well with those obtained with the previously described monostarter assay, performed at $\mathrm{pH} 9.2(\mathrm{y}=0.60 \mathrm{x}+37 ; \mathrm{n}=80 ; \mathrm{r}=0.991)$. Results of 6-phosphogluconate dehydrogenase (U/l) in whole blood $(y)$ correlated well with those obtained by the ICSH recommended method $(x)(y=0.779 x-44 ; n=23 ; r=0.991)$. Reference intervals are reported for glucose 6phosphate dehydrogenase, 6-phosphogluconate dehydrogenase and glucose 6-phosphate dehydrogenase/6-phosphogluconate dehydrogenase index relatively to normal, $\beta$ - and $\alpha$-thalassaemic glucose 6-phosphate dehydrogenase non-deficient adults, to glucose 6-phosphate dehydrogenase deficient adult males and to G6PD Mediterrancan nonthalassaemic heterozygotes. We demonstrate that the diagnostic sensitivity of the glucose 6-phosphate dehydrogenase/6-phosphogluconate dehydrogenase index in detecting the G6PD ${ }^{\text {Mediterranean }}$ heterozygotes is superior to that of the glucose 6-phosphate dehydrogenase activity alone.

\section{Introduction}

The quantitative determination of glucose 6-phosphate dehydrogenase ${ }^{2}$ ) activity is clinically important in cases of chronic non-spherocytic haemolytic anaemia, or in episodic haemolytic anaemia caused by drugs or infections (1). The test must also be performed in cases of severe neonatal jaundice and before the administration of oxidant haemolytic drugs, while its use in transfusional medicine is controversial, although posttransfusional haemolytic reactions were seldom demonstrated in recipients of glucose 6-phosphate dehydrogenase-de-

\footnotetext{
1) Funding organisation:

Work partially supported by Target Project BTBS, CNR and by M. U.R.S.T. $60 \%$.

2) Enzymes

Glucose 6-phosphate dehydrogenase (D-Glucose 6-phosphate : NADP oxidoreductase, EC 1.1.1.49);

Phosphogluconate dehydrogenase (6-phospho-D-gluconate NADP oxidoreductase, decarboxylating, EC 1.1.1.44).
}

ficient erythrocytes (2). Finally, the determination of glucose 6-phosphate dehydrogenase activity is indicated for the detection of heterozygote females. As a curiosity, severe deficiency of glucose 6-phosphate dehydrogenase has recently been reported in horses, so that the determination of glucose 6-phosphate dehydrogenase activity could also be of interest in veterinary medicine (3).

In European countries, glucose 6-phosphate dehydrogenase deficiency is frequently associated with the glucose 6-phosphate dehydrogenase ${ }^{\text {Mediterranean }}$, a variant with very low activity. The highest frequency is found in Greece (overall frequency of male glucose 6-phosphate dehydrogenase deficiency: $18 \%$ ), followed by Sardinia $(15 \%)$, North Italy (2\%) and Spain (1\%) (4-6). However, because of recent immigrations from high incidence areas, cases of glucose 6-phosphate dehydrogenase deficiency can also be found in the major industrial cities of Central and Northern Europe. 
Several spectrophotometric methods are available for accurately determining glucose 6-phosphate dehydrogenase activity, which has to be measured free of interference from 6-phosphogluconate dehydrogenase ${ }^{2}$ ) activity. This can be accomplished by inhibiting the 6-phosphogluconate dehydrogenase activity with maleimide (7) or by subtraction of the 6-phosphogluconate dehydrogenase activity, performed in a separate set of measurements, as recommended by the WHO protocol (8). Some years ago, as an alternative to the spectrophotometric assay, a new rapid potentiometric method for the quantitative determination of glucose 6-phosphate dehydrogenase in whole blood and isolated red cells was presented (9). Such an assay was successfully applied to the glucose 6-phosphate dehydrogenase deficiency detection in areas with high prevalence of the disease (10). The method was based on differential $\mathrm{pH}$ measurements performed directly on $10 \mu \mathrm{l}$ whole blood and was later followed by protocols for the determination of other red cell enzymes activities $(11,12)$.

A problem common to the different techniques for glucose 6-phosphate dehydrogenase activity determination and, more generally, to the determination of the activity of any red cell enzyme, concerns the expression of the enzymatic activity. This can be reported in terms of $\mathrm{U} / \mathrm{g} \mathrm{Hb}$, the most frequently used units, or in terms of units per fixed number of erythrocytes (U/10 12 erythrocytes). However, in cases of anaemias not associated with glucose 6-phosphate dehydrogenase deficiency, such as iron deficiency or $\beta$-thalassaemia trait (10), higher than normal glucose 6 -phosphate dehydrogenase activities are found with both units. As a consequence, separate reference intervals for the various syndromes are needed.

In this report we present a new protocol for the simultaneous determination of the glucose 6-phosphate dehydrogenase/6-phosphogluconate dehydrogenase index in whole blood, by using an improved version of the differential $\mathrm{pH}$ system already applied to the determination of glucose 6-phosphate dehydrogenase activity (9). We also report on the utility of the glucose 6-phosphate dehydrogenase/6-phosphogluconate dehydrogenase index in a geographic area with a high prevalence of glucose 6-phosphate dehydrogenase deficiency and thalassaemic syndromes. Finally, by using a rapid method suitable for identifying the glucose 6-phosphate dehydrogenase ${ }^{\text {Medi- }}$ terranean variant at the DNA level, we evaluate the genotype-phenotype relationship in a subgroup of heterozygotes for the G6PD Mediterranean variant.

\section{Materials and Methods}

Specimens

Blood samples collected in sodium EDTA for routine laboratory complete blood counts were analysed shortly after withdrawal.
Erythrocytes freed from leukocytes and platelets were prepared by blood filtration through $\alpha$-cellulose and microcrystalline cellulose (13).

All the cell count values of normocytic samples (from subjects between $16-17$ years of age) were within normal ranges. The diagnosis of $\beta$-thalassaemia trait was based on increased $\mathrm{Hb} \mathrm{A}_{2}$ levels $(>3.5 \%)$ associated with microcytosis, reduced $\mathrm{MCH}^{3}$ ) and normal serum iron. $\alpha$-Thalassaemia trait was suspected in subjects showing reduced $\mathrm{MCV}^{3}$ ) and $\mathrm{MCH}$, normal serum iron, $\mathrm{Hb} \mathrm{A}_{2}$ and $\mathrm{Hb}$ F. The diagnosis of $\alpha$-thalassaemia trait was confirmed by globin synthesis $(\alpha / \beta$ ratio $<0.9)$ or $\alpha$ globin 'gene DNA analysis

Glycerol-stabilised haemolysates for use as control material were prepared as described (14). The low glucose 6-phosphate dehydrogenase activity lot was prepared by warming an aliquot of the normal activity batch at $50^{\circ} \mathrm{C}$ for $50 \mathrm{~min}$.

\section{Instrumentation}

The analyses were performed at $37^{\circ} \mathrm{C}$ on a differential $\mathrm{pH}$ analyser (CL50, Eurochem srl, 00040 Ardea, Rome, Italy) equipped with cell top and software for double starter procedures. Total blood cell count and haemoglobin concentration were determined with a Coulter S Plus electronic counter (Kontron AG). $\mathrm{Hb} \mathrm{A_{2 }}$ was quantified with the HPLC Variant (Bio-Rad Laboratories, Milano, Italy).

\section{Principle of the assays}

The glucose 6-phosphate dehydrogenase and 6-phosphogluconate dehydrogenase activities were measured by following the $\mathrm{pH}$ changes produced in the reaction buffer during the conversions of $\mathrm{NADP}^{+}$to NADPH and $\mathrm{H}^{+}$.

\section{Working solutions}

A stock buffer with the following composition was prepared: TRIS (10 mmol/l), $\mathrm{KCl}(100 \mathrm{mmol} / \mathrm{l}), \mathrm{MgCl}_{2}$ (10 mmol/l), EDTA (0.5 mmol/l), $\mathrm{NaN}_{3}(\mathrm{~g} / \mathrm{l})$ and Triton X-100 (1 g/l). Its pH was lowered to 8.6 with concentrated $\mathrm{HCl}$. The solution was stable one month at room temperature. The working buffer was prepared by adding NADP $0.6 \mathrm{mmol} / \mathrm{l}$, final concentration. The $\mathrm{pH}$ of the working buffer was $8.00 \pm 0.05$ at $25^{\circ} \mathrm{C}$. It was prepared fresh every week. Glucose 6-phosphate $(65 \mathrm{mmol} / \mathrm{l})$ in $\mathrm{NaN}_{3}(1 \mathrm{~g} / \mathrm{l})$ and 6-phosphogluconate $(25 \mathrm{mmol} / \mathrm{l})$, both at $\mathrm{pH} 8.0$ were prepared fresh every week and stored at $+4^{\circ} \mathrm{C}$.

\section{Differential $\mathrm{pH}$ procedures}

The assays were performed on $25 \mu$ l of whole blood, with 6-phosphogluconate added as starter 1 and glucose 6-phosphate as starter 2.

The sample was added manually to the mixing chamber filled with $1170 \mu \mathrm{l}$ of the working buffer. After dilution and lysis of the red cell membranes $(10 \mathrm{~s})$, part of the reaction mixture was automatically injected into each of the capillary electrodes, and $15 \mu \mathrm{l}$ of the first starter were added to the mixing chamber, which contained $800 \mu \mathrm{l}$ of the reaction mixture. After further mixing, this reaction mixture plus substrate was injected into only one electrode. The variation of $\mathrm{pH}$ between the two electrodes after a lag phase of $30 \mathrm{~s}$ was recorded for $30 \mathrm{~s}$ and used to calculate the 6-phosphogluconate dehydrogenase enzymatic activity. For the measurement of the second enzymatic activity $15 \mu \mathrm{l}$ of the second starter were added to the mixing chamber, which contained $300 \mu$ l of the reaction mixture. After further mixing, this reaction mixture plus substrate was injected into the other electrode. The variation of $\mathrm{pH}$ between the two electrodes after a lag phase of $30 \mathrm{~s}$ was recorded for $30 \mathrm{~s}$ and used to calculate the glucose 6-phosphate dehydrogenase enzymatic activity.

\footnotetext{
3) $\mathrm{MCH}=$ Mean corpuscular haemoglobin

$\mathrm{MCV}=$ Mean corpuscular volume
} 
Tab. 1 Reproducibility for whole blood samples.

\begin{tabular}{|c|c|c|c|c|c|c|c|c|}
\hline \multicolumn{3}{|c|}{$\begin{array}{l}\text { Glucose 6-phosphate } \\
\text { dehydrogenase }\end{array}$} & \multicolumn{3}{|c|}{$\begin{array}{l}\text { 6-Phosphogluconate } \\
\text { dehydrogenase }\end{array}$} & \multicolumn{3}{|c|}{$\frac{\text { Glucose 6-phosphate dehydrogenase }}{\text { 6-Phosphogluconate dehydrogenase }}$} \\
\hline $\begin{array}{l}\text { Mean } \\
(\mathrm{U} / \mathrm{l})\end{array}$ & $\begin{array}{l}S D \\
(U / 1)\end{array}$ & $\begin{array}{l}\text { CV } \\
(\%)\end{array}$ & $\begin{array}{l}\text { Mean } \\
(\mathrm{U} / \mathrm{l})\end{array}$ & $\begin{array}{l}S D \\
(U / 1)\end{array}$ & $\begin{array}{l}\text { CV } \\
(\%)\end{array}$ & Mean & $S D$ & $\begin{array}{l}\text { CV } \\
(\%)\end{array}$ \\
\hline $\begin{array}{r}1040 \\
329 \\
51\end{array}$ & $\begin{array}{r}10 \\
8 \\
11\end{array}$ & $\begin{array}{r}1.0 \\
2.3 \\
21.7\end{array}$ & $\begin{array}{l}768 \\
835 \\
946\end{array}$ & $\begin{array}{l}44 \\
21 \\
13\end{array}$ & $\begin{array}{l}5.8 \\
2.5 \\
1.4\end{array}$ & $\begin{array}{l}1.36 \\
0.40 \\
0.06\end{array}$ & $\begin{array}{l}0.08 \\
0.01 \\
0.01\end{array}$ & $\begin{array}{r}5.9 \\
2.5 \\
21.7\end{array}$ \\
\hline $\begin{array}{l}946 \\
345\end{array}$ & $\begin{array}{l}23 \\
13\end{array}$ & $\begin{array}{l}2.4 \\
3.6\end{array}$ & $\begin{array}{l}779 \\
845\end{array}$ & $\begin{array}{l}22 \\
26\end{array}$ & $\begin{array}{l}2.8 \\
3.1\end{array}$ & $\begin{array}{l}1.22 \\
0.41\end{array}$ & $\begin{array}{l}0.05 \\
0.02\end{array}$ & $\begin{array}{l}4.1 \\
4.9\end{array}$ \\
\hline
\end{tabular}

Within-run $(\mathrm{n}=20)$

Normal subjects

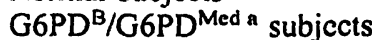

G6PD ${ }^{\text {Med b }}$ subjects

Between-run $(\mathrm{n}=38)$

Normal activity

Low activityd

a Glucose 6-phosphate dehydrogenase heterozygous female

b Glucose 6-phosphate dehydrogenase deficient male

c Glycerol-stabilised haemolysate

d Glycerol-stabilised haemolysate, heat-treated $\left(50^{\circ} \mathrm{C}, 50 \mathrm{~min}\right)$

An autosampler with capacity for 50 samples was loaded automatically with the specimen ( $300 \mu \mathrm{l}$ whole blood per vial). The autosampler probe tip aspirated from the bottom of each sample vial and injected $25 \mu \mathrm{l}$ of sample into the mixing chamber of the differential $\mathrm{pH}$ apparatus.

Calculations of the enzymatic activities were automatically performed by the instrument, as described for other enzymatic assays $(9,12)$. The following main instrumental variables were set: slope 1: -186 ; slope 2: 93 .

The glucose 6-phosphate dehydrogenase activity was also measured under optimised conditions with the differential $\mathrm{pH}$ technique, using the previously described monostarter kit (10).

\section{DNA analysis}

Genomic DNA was isolated from leukocytes and purified by the method of Goossens \& Kan (15). The polymerase chain reaction (PCR) was carried out according to Saiki et al. (16). The Mediterranean glucose 6-phosphate dehydrogenase mutation was detected according to Kurdi-Haidar et al. (17). The G6PD Mediterranean mutation at position $563(\mathrm{C} \rightarrow \mathrm{T})$, creates a novel $M$ bo II site in exon VI of the glucose 6-phosphate dehydrogenase gene. To identify subjects carring this mutation a fragment containing exons VI and VII was amplified using the following primers:

(a) 5' ACTCCCGAAGAGGGGTTCCAAGG 3',

(b) 3' GAAGGAGAGAGGACCCTCCGACC 5'.

The DNA amplified fragment was digested with Mbo II restriction enzyme and the digestion fragments were analysed on agarose gel.

\section{Statistical analysis}

The results were analysed by a commercial statistical program (LABSTAT vs 3.03, Bio-Rad Laboratories, Milano). Kurtosis, asymmetry and Kolmogorov-Smirnov's tests were used to determine whether distributions were Gaussian. Means of duplicate assays were used for evaluating between-run reproducibility. Groups were compared by the Wilcoxon test for unpaired observations. The Pearson correlation coefficient was calculated to compare the association between variables. Linear regression analysis was performed with the least-squares method. Values of $\mathrm{P}<0.05$ were considered statistically significant.

\section{Results}

Under our experimental conditions the lag and measuring times were found adequate to obtain steady state kinetics. In terms of $\mathrm{pH}$ change per minute, a normal sample gave approximatively $0.006 \mathrm{pH} / \mathrm{min}$ and 0.013 $\mathrm{pH} / \mathrm{min}$ with the 6-phosphogluconate dehydrogenase and glucose 6-phosphate dehydrogenase reactions, respectively.

The within-run reproducibility (tab. 1) was assessed by measuring twenty times three samples with normal and reduced glucose 6-phosphate dehydrogenase activities. The glucose 6-phosphate dehydrogenase activity had the best score in terms of $\mathrm{CV}$, but both glucose 6-phosphate dehydrogenase and 6-phosphogluconate dehydrogenase activities were measured with similar SD, in terms of U/l.

The between-run reproducibility was evaluated by measuring, during four months, two glycerol-stabilised haemolysates; it was found to be similar to the withinrun reproducibility. The coefficient of variations calculated, in the same period, on blood specimens measured in duplicate, were $3.9 \%, 4.9 \%$ and $5.3 \%$ for the glucose 6-phosphate dehydrogenase activity, 6-phosphogluconate dehydrogenase activity and glucose 6-phosphate dehydrogenase/6-phosphogluconate dehydrogenase index, respectively.

The linearity test was performed by assaying 11 serial dilutions of washed erythrocytes isolated from a nondeficient adult male (glucose 6-phosphate dehydrogenase $1361 \mathrm{U} / \mathrm{l}$; glucose 6-phosphate dehydrogenase/6phosphogluconate dehydrogenase index 1.69 ) with the red cells obtained from a glucose 6-phosphate dehydrogenase deficient male (glucose 6-phosphate dehydrogenase $35 \mathrm{U} / 1$; glucose 6-phosphate dehydrogenase/6phosphogluconate dehydrogenase index 0.04). Each aliquot was measured in triplicate. The linear-regression analysis of the glucose 6-phosphate dehydrogenase activity $(y, U / 1)$ vs. the percentage of the "high activity sample" $(\mathrm{x})$ calculated on the 5 dilutions at lower activ- 
ity concentration was as follows: $y=12.9 x+35.6$; $r=0.9996$. Moreover, the linear-regression analysis of the glucose 6-phosphate dehydrogenase/6-phosphogluconate dehydrogenase index $\left(y^{\prime}\right)$ vs. the percentage of the "high activity sample" ( $\left.x^{\prime}\right)$ calculated on the same 5 dilutions at lower activity concentration was: $y^{\prime}=0.017 x^{\prime}+0.032 ; r=0.9981$. Using these regression equations we calculated the theoretical values for the other 6 dilutions, and the biases between the theoretical and the found. The mean bias relative to the glucose 6-phosphate dehydrogenase linearity test was $-0.8 \%$, and that relative to the glucose 6-phosphate dehydrogenase/6-phosphogluconate dehydrogenase index linearity test was $4.8 \%$. Therefore, both methods were considered linear. The correlation between the 6-phosphogluconate dehydrogenase activity and the percentage of the "high activity sample" was not significant $(r=0.192)$.

Linearity was also assessed on blood samples, using volumes between 5 and $80 \mu \mathrm{l}$. The glucose 6-phosphate dehydrogenase and 6-phosphogluconate dehydrogenase activities were directly proportional to sample volumes between 5 and $50 \mu \mathrm{l}$, but deviations from linearity were found for larger sample volumes. On the other hand, the measurement of the glucose 6-phosphate dehydrogenase/6-phosphogluconate dehydrogenase index was found to be essentially independent of the sample volume.

Accuracy was assayed separately for glucose 6-phosphate dehydrogenase and 6-phosphogluconate dehydrogenase activities. Figure 1 illustrates the results of the comparison of the glucose 6-phosphate dehydrogenase activities measured by the proposed method and by the previously described method performed with the monostarter kit. Glucose 6-phosphate dehydrogenase activities were well correlated (left graph of fig. 1). The glucose 6-phosphate dehydrogenase/6-phosphogluconate

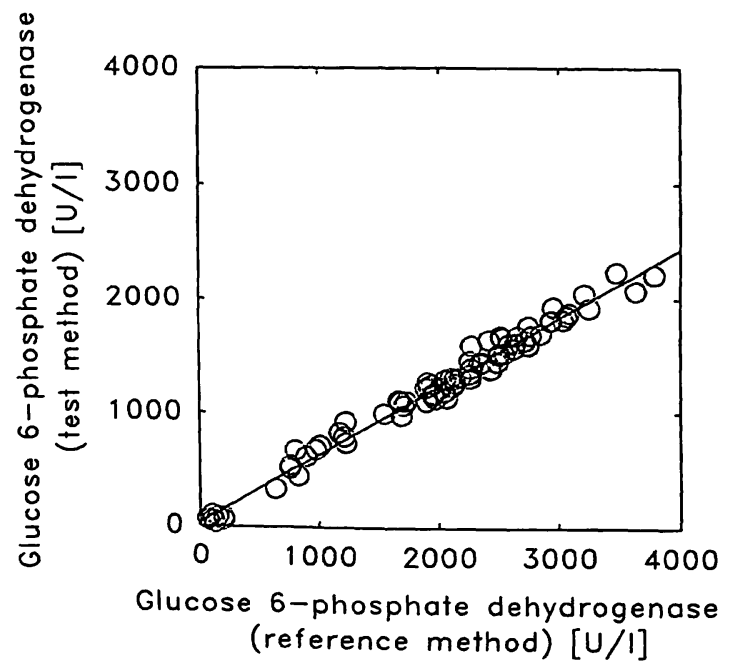

Fig. 1 Comparison between the presently described methods (y) and the previously reported optimised glucose 6-phosphate dehydrogenase assay test $(x)$ for glucose 6-phosphate dehydrogenase activity (left; regression line: $y=0.60 x+37 ; n=80 ; r=0.991$; dehydrogenase index was also well correlated with the glucose 6-phosphate dehydrogenase activity, but the standard error of the estimate $\left(S_{y x}\right)$ indicated a slightly higher dispersion of the sample data points around the regression line. The 6-phosphogluconate dehydrogenase activity measured by the proposed method was compared with that measured, on the same samples, by the ICSH reference method. These results, shown in figure 2 , proved a good correlation between' the proposed and the reference method.

The performance of the autosampler was tested by running five times a set of eight samples from glucose 6phosphate dehydrogenase non-deficient adult males and three samples of heterozygotes for the G6PD Mediterranean variant. From each sample $300 \mu \mathrm{l}$ of whole blood were directly loaded into the autosampler tubes, which were then processed in series. Figure 3 shows the results of this test. As can be seen, as a result of erythrocyte sedimentation in the tubes, both glucose 6-phosphate dehy-

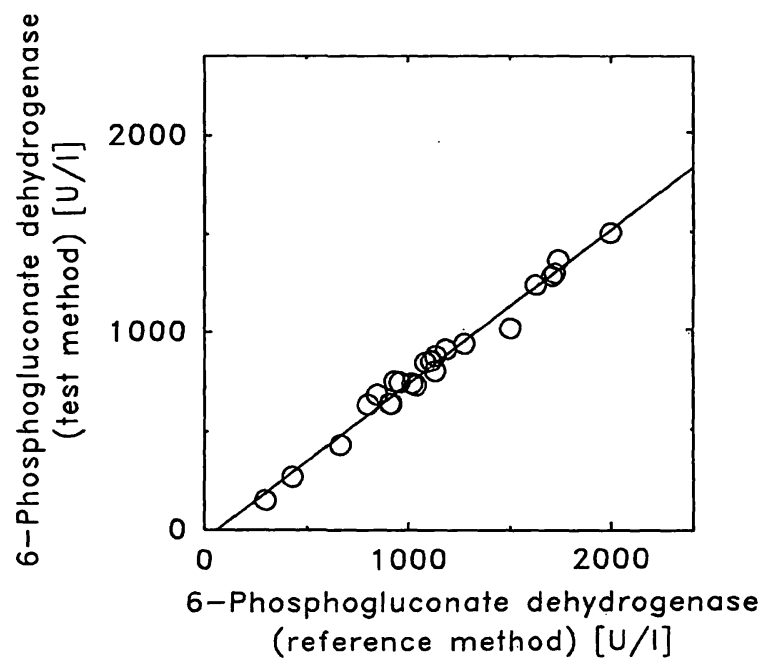

Fig. 2 Comparison between the differential $\mathrm{pH}$ and the ICSH methods for 6-phosphogluconate dehydrogenase activity.

Regression line: $y=0.779 x-44 ; n=23 ; r=0.991 ; S_{y x}=45$.

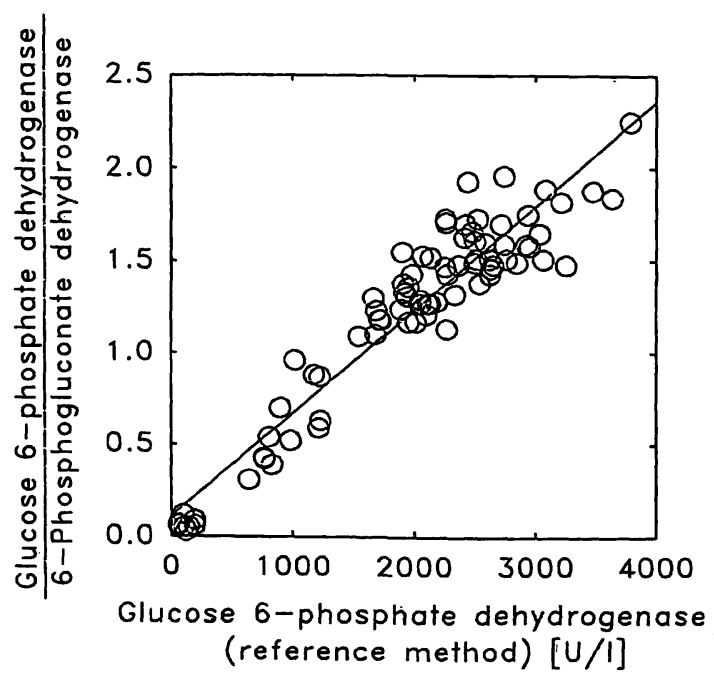

$\left.S_{y x}=75\right)$ and the glucose 6-phosphate dehydrogenase/6-phosphogluconate dehydrogenase index (right; regression line: $y=0.0006 x$ $\left.+0.11 ; \mathrm{n}=80 ; \mathrm{r}=0.948 ; \mathrm{S}_{\mathrm{yx}}=0.18\right)$. 


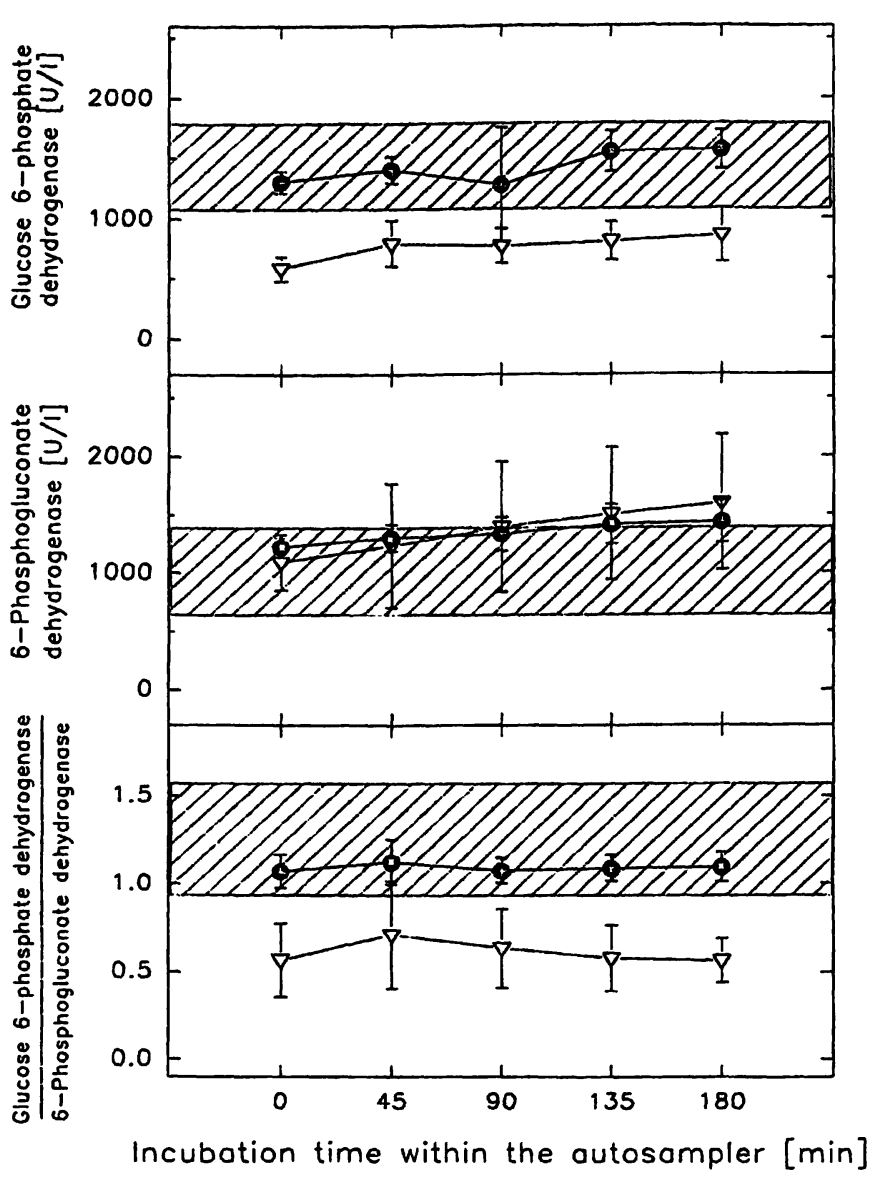

Fig. 3 Performance of the autosampler loaded with undiluted whole blood samples. The same batches of normal males (full circles; $n=8$ ) and of heterozygous G6PD Mediterranean females (open triangles; $n=3$ ) were analysed at different times after loading in the autosampler. The reference intervals are depicted by the dashed areas. Each point is the average of the batch.

drogenase and 6-phosphogluconate dehydrogenase activities tend to increase after standing in the autosampler for different times before the analysis. However, the glucose 6-phosphate dehydrogenase/6-phosphogluconate dehydrogenase index was found to be totally independent from this phenomenon, with a concomitant sig- nificant discrimination of the glucose 6-phosphate dehydrogenase-deficient samples from normals.

Table 2 reports the reference intervals partitioned by sex and by the presence of $\alpha$ - or $\beta$-thalassaemia. In the males G6PD Mediterranean -positive group, visual inspection of the distributions and statistical analysis indicated that, in the presence of $\beta$-thalassaemia, the $\mathrm{U} / \mathrm{g} \mathrm{Hb}$ of both enzymes and the glucose 6-phosphate dehydrogenase/6phosphogluconate dehydrogenase indexes were all shifted to higher values $(P<0.001$ for all the comparisons). In the G6PD ${ }^{\text {Meditcrancan }}$-positive males with $\alpha$-thalassaemia the activities were still significantly higher than in normals, although to a lesser extent. In the few cases of subjects with iron deficiency (not shown) we observed an intermediate pattern between the $\alpha$ - and $\beta$ thalassaemia carriers. 6-Phosphogluconate dehydrogenase activity was significantly different between normal G6PD Mediterranean-positive males and normal G6PD ${ }^{\text {Medit- }}$ erranean-positive females, with the latter showing the higher activities $(P<0.001)$.

The DNA analysis of glucose 6-phosphate dehydrogenase gene with particular attention to the presence of the G6PD Mediterranean variant is reported in figure 4 . The PCR amplified region of the glucose 6-phosphate dehydrogenase gene encompassing exons VI and VII is a fragment of 547 base pairs (fig. 4, lane 1). The fragments obtained from a glucose 6-phosphate dehydrogenase normal subject after $M b o$ II digestion and visible on the gel are of 377 base pairs and 119 base pairs (fig. 4 , lane 2). The presence of the $C \rightarrow T$ mutation at position 563 in exon VI of the glucose 6-phosphate dehydrogenase gene creates a novel Mbo II site, so that heterozygotes for G6PD Mediterrancan show, in addition to the 377 base pairs and 119 base pairs fragments, two bands of 277 base pairs and of 100 base pairs, respectively (fig. 4 , lane 3 ). Subjects homozygote for G6PD Mediterranean

Tab. 2 Reference intervals. Data are expressed as means \pm SD. Parametric centiles 2.5-97.5, calculated for $n \geq 30$, in italics. 6-Phosphogluconate dehydrogenase and glucose 6-phosphate dehydrogenase activities are in terms of $\mathrm{U} / \mathrm{g} \mathrm{Hb}$.

n Glucose 6-phosphate dehydrogenase $(\mathrm{U} / \mathrm{g} \mathrm{Hb})$
6-Phosphogluconate dehydrogenase $(\mathrm{U} / \mathrm{g} \mathrm{Hb})$
Glucose 6-phosphate dehydrogenase 6-Phosphogluconate dehydrogenase

Males, glucose 6-phosphate dehydrogenase non-deficient phenotype

Non-Thalassaemic

$\beta$-Thalassaemia

$\alpha$-Thalassaemia

\section{9}

27

19
$8.6 \pm 1.0$

$6.6-10.6$

$15.6 \pm 2.1$

$10.3 \pm 1.4$
$6.6 \pm 0.8$

$5.0-8.2$

$9.4 \pm 1.5$

$7.2 \pm 0.9$
$1.32 \pm 0.19$

$0.95-1.68$

$1.69 \pm 0.24$

$1.45 \pm 0.18$

Males, glucose 6-phosphate dehydrogenase deficient phenotype

$\begin{array}{lll}\text { Non-Thalassaemic } & 7 & 0.7 \pm 0.5 \\ \beta \text {-Thalassaemia } & 3 & 0.7 \pm 0.2 \\ \alpha \text {-Thalassaemia } & 2 & 0.6\end{array}$

$7.2 \pm 0.5$
$8.9 \pm 0.9$
7.8

$0.10 \pm 0.06$

$0.08 \pm 0.04$

0.08

Females, glucose 6-phosphate dehydrogenase non-deficient phenotype

Non-Thalassaemic

30

$8.3 \pm 1.5$

$8.0 \pm 1.0$

$1.05 \pm 0.23$

$5.4 \pm 11.1$

$6.1 \pm 10.0$

$0.59-1.50$ 


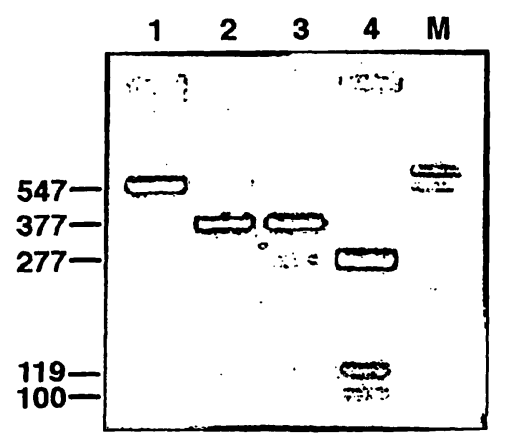

Fig. 4 Restriction enzyme analysis of amplified glucose 6-phosphate dehydrogenase gene.

Lane 1: undigested amplified fragment;

lane 2: normal control;

lane 3: heterozygous female for G6PD

lane 4: homozygous female for G6PD Mediterranean;

lane 5: size markers (pBR $322 \mathrm{ksp}$ I digested).

Numbers of base pairs relative to the main bands are on the left.

showed only fragments of 277 base pairs, 119 base pairs and 100 base pairs (fig. 4, lane 4).

Finally, a comparison of the diagnostic sensitivities of the properties glucose 6-phosphate dehydrogenase activity and glucose 6-phosphate dehydrogenase/6-phosphogluconate dehydrogenase index was performed with the help of the data presented in figure 5. The glucose 6phosphate dehydrogenase activity in $25 \mathrm{G} 6 \mathrm{PD}^{\text {Mediterra- }}$ ncan heterozygote women was $5.96 \pm 1.62 \mathrm{U} / \mathrm{g} \mathrm{Hb}$ (mean $\pm \mathrm{SD}$ ). In 4 subjects the glucose 6-phosphate dehydrogenase activity was within the reference intervals established on normal non-deficient adult males, while in $21 / 25(84.0 \%)$ subjects the glucose 6-phosphate dehydrogenase activity was below such reference intervals. However, the glucose 6-phosphate dehydrogenase/6phosphogluconate dehydrogenase index in the same subjects was $0.64 \pm 0.19$. In only one subject the index was within the reference intervals established on normal nondeficient adult males, while in 24/25 of the heterozygote women $(96.0 \%)$ the glucose 6-phosphate dehydroge-

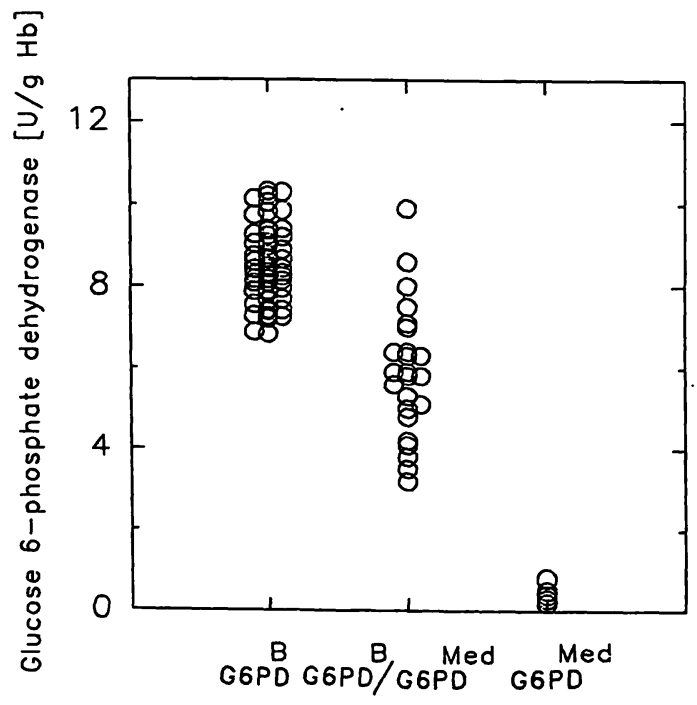

Fig. 5 Glucose 6-phosphate dehydrogenase (left) and glucose 6phosphate dehydrogenase/6-phosphogluconate dehydrogenase (right) distributions in 59 normal glucose 6-phosphate dehydroge- nase/6-phosphogluconate dehydrogenase index was below the reference intervals of the normal G6PD Mediterranoan-positive males.

\section{Discussion}

A new method for the rapid determination of glucose 6phosphate dehydrogenase activity in whole blood with the differential $\mathrm{pH}$ technique is presented. This method requires $25 \mu \mathrm{l}$ of whole blood, is automated and seems quite reliable. The assay conditions differ from those previously reported (10) principally with regard to the following points:

(a) the working $\mathrm{pH}$ is 8.0 instead of 9.2 , and the buffer has been changed (TRIS $10 \mathrm{mmol} / \mathrm{l}, \mathrm{KCl} 100 \mathrm{mmol} / \mathrm{l}$ and EDTA $0.5 \mathrm{mmol} / \mathrm{l}$ instead of glycylglycine 7.0 $\mathrm{mmol} / \mathrm{l}$, glycine $6.5 \mathrm{mmol} / \mathrm{l}$ and $\mathrm{KCl} 150 \mathrm{mmol} / \mathrm{l}$ );

(b) the 6-phosphogluconate dehydrogenase activity is measured separately from that of glucose 6-phosphate dehydrogenase so that the glucose 6-phosphate dehydrogenase/6-phosphogluconate dehydrogenase index can be calculated.

The new $\mathrm{pH}$ and buffer were essential, in order to obtain a sufficiently strong signal from the 6-phosphogluconate dehydrogenase activity, which at $\mathrm{pH} 9.2$ is inhibited by almost $80 \%$ (9). Therefore, we decided not to optimise the old protocol but to present a new method that correlates well with the ICSH standard assay (13). Under the actual conditions, both glucose 6-phosphate dehydrogenase and 6-phosphogluconate dehydrogenase activities can be measured with good reproducibility, although maximal enzyme activity is not attained. In fact, the agreement between our and ICSH method for both glucose 6-phosphate dehydrogenase and 6-phosphogluconate dehydrogenase is good. Moreover, the glucose 6phosphate dehydrogenase reference interval for normal

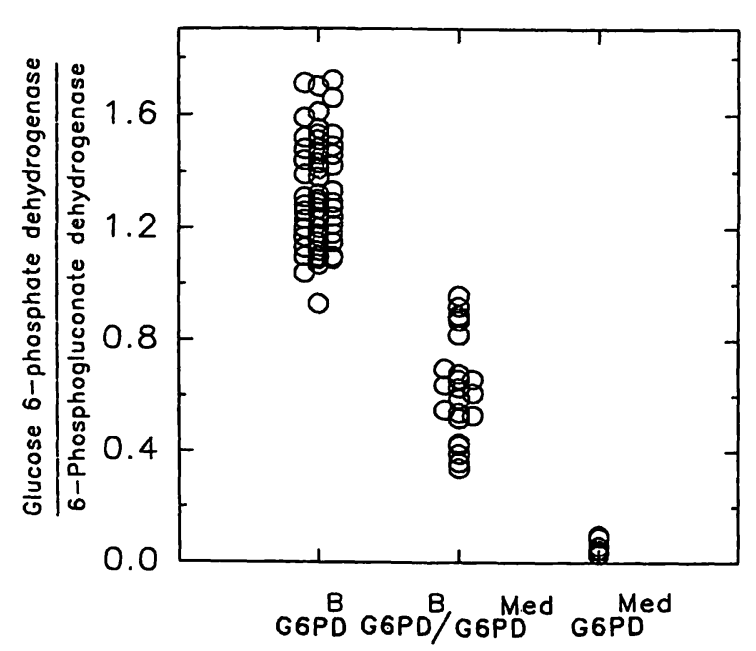

nase non-deficient males $G 6 \mathrm{PD}^{\mathrm{B}}$, in $25 \mathrm{G} 6 \mathrm{PD}^{\text {Mediterranean }}$ female carriers (G6PD ${ }^{\mathrm{B}} / \mathrm{G} \mathrm{PD}^{\mathrm{Med}}$ ) and in 9 glucose 6-phosphate dehydrogenase deficient males (G6PD ${ }^{\mathrm{Med}}$ ). 
non-deficient males established by the differential $\mathrm{pH}$ method $(8.6 \pm 1.0 \mathrm{U} / \mathrm{g} \mathrm{Hb})$ is very close to that reported by the ICSH committee for a group of only 10 subjects $(8.3 \pm 1.6 \mathrm{U} / \mathrm{g} \mathrm{Hb}$; (13)).

With regard to the new double-starter procedure here reported, preliminary experiments indicated that the 6phosphogluconate dehydrogenase activity is correctly evaluated by the new double-starter procedure reported here, irrespective of whether 6-phosphogluconate is the first or second substrate added to the mixing chamber. Particular attention should be paid to the stability of the 6-phosphogluconate solution. It cannot be stored at $4{ }^{\circ} \mathrm{C}$ for more than five days, since 6-phosphogluconate is then hydrolysed and its concentration becomes rate-limiting. We also noticed significant differences in the 6phosphogluconate dehydrogenase activity measured with 6-phosphogluconate purchased from Sigma or Boehringer, and also between different batches of the Boehringer reagent. It has already been reported that contamination with impurities varies greatly from manufacturer to manufacturer and between lots (18). The use of appropriate control materials, such as glycerol-stabilised haemolysates (14), allows for the detection of such differences and for an eventual correction of the data.

The measurement of the glucose 6-phosphate dehydrogenase/6-phosphogluconate dehydrogenase index by the proposed method significantly improves the sensitivity of detection of the heterozygotes for G6PDMcditerranean. This is probably due to the restricted distribution of the enzymatic activities, both in normal and in heterozygotes. Among our group of heterozygotes the glucose 6- phosphate dehydrogenase/6-phosphogluconate dehydrogenase indexes were homogenously distributed, without any evidence of the extreme phenotypes previously found by Rinaldi et al. (19), and with an incidence of approximately $5.1 \%$ among the heterozygotes. Moreover, the distribution of glucose 6-phosphate dehydrogenase/6-phosphogluconate dehydrogenase red cell activities in our sample of 25 Sardinian heterozygotes for the G6PD Mediterranean mutant was essentially uniform, without any skew toward the normal non-deficient subjects. This finding could be of interest in view of the extensive use of glucose 6-phosphate dehydrogenase and other Xlinked markers as probes of monoclonality in cell populations.

The use of the autosampler loaded directly with undiluted blood specimen significantly reduces the laboratory work load and does not require any specialized knowledge of the differential $\mathrm{pH}$ apparatus. In doubtful cases, the described simple method of DNA analysis permits the definition of the genotype relative to the occurrence of the G6PD ${ }^{\text {Mediterrancan }}$ mutant. Other classical cytochemical methods can be performed to assess the genotype in the presence of rarer glucose 6-phosphate dehydrogenase variants $(20,21)$.

\section{Acknowledgements}

We wish to acknowledge Giancarlo Caramenti (I. T.B. A., CNR) for invaluable technical help. This work was supported in part by Progetto Finalizzato Biotecnologie e Biostrumentazione, Consiglio Nazionale delle Ricerche.

\section{References}

1. Beutler E. Glucose-6-phosphate dehydrogenase deficiency. In: Standbury JB, Wyngaarden JB, Fredrikson DS, Goldstein JL, Brown MS, editors. The metabolic basis of inherited disease. New York: McGraw-Hill, 1983;1629-53.

2. Shalev O, Manny N, Sharon R. Posttransfusional hemolysis in recipients of glucose-6-phosphate dehydrogenase-deficient erythrocytes. Vox Sang 1993; 64:94-8.

3. Stockham SL, Harvey JW, Kinden DA. Equine glucose-6phosphate dehydrogenase deficiency. Vet Pathol 1994; 31:518-27.

4. Luzzatto L, Battistuzzi G. Glucose 6-phosphate dehydrogenase. Adv Hum Genet 1985; 14:217-329.

5. Missiou-Tsagaraki S. Screening for glucose-6-phosphate dehydrogenase deficiency as a preventive measure: prevalence among 1,286,000 Greek newborn infants. J Pediatr 1991; 119:293-9.

6. Testa U, Meloni T, Lania A, Battistuzzi G, Cutillo S, Luzzatto L. Genetic heterogeneity of glucose 6-phosphate dehydrogenase deficiency in Sardinia. Hum Genet 1980; 56:99-105.

7. Deutsch J. Maleimide as a inhibitor in measurement of erythrocyte glucose 6-phosphate dehydrogenase activity. Clin Chem $1978 ; 24: 885-8$.

8. WHO Scientific Group. Standardization of procedures for the study of glucose 6-phosphate dehydrogenase. World Health Organization, Geneva 1967.

9. Barenghi L, Ceriotti F, Ripamonti M, Luzzana M, Bonini PA. Erythrocytic glucose-6-phosphate dehydrogenase measured by a differential pH technique. Clin Chem 1987; 33:579-82.

10. Mosca A, Paderi M, Sanna A, Paleari R, Cao A, Galanello R. Preliminary experience with the differential $\mathrm{pH}$ technique for glucose-6-phosphate dehydrogenase (G6PD) measurement in whole blood: application to an area with high prevalence of thalassaemia and G6PD deficiency. Haematologica 1990; 75:397-9.

11. Mosca A, Tagarelli A, Paleari R, Scarpelli P, Brancati C. Rapid determination of erythrocyte pyruvate kinase activity. Clin Chem 1993; 39:512-6.

12. Mosca A, Onelli E, Rosti E, Paleari R, Luzzana M, Imbimbo BP. A patient-side technique for real-time measurement of acetylcholinesterase activity during monitoring of eptastigmine treatment. Therap Drug Monit 1995; 17:230-8.

13. Beutler E, Blume KG, Kaplan JC, Lohr GW, Ramot B, Valentine WN. International Committee for Standardization in Haemology: recommended methods for red-cell enzyme analysis. Br J Haematol 1977; 35:331-40.

14. Paleari R, Ceriotti F, Bonini PA, Mosca A. Standardization problems relevant to quantitative laboratory methods for glucose 6-phosphate dehydrogenase deficiency detection. Giorn It Chim Clin 1990; 15:191-8.

15. Gossens M, Kan YE. DNA analysis in the diagnosis of hemoglobin disorders. Methods Enzymol 1981; 76:805-17. 
16. Saiki RK. Gelfand DH, Stoffel S, Scharf SJ, Higuchi R, Hom GT, et al. Primer-directed enzymatic amplification of DNA with a thermostable DNA polymerase. Science 1988; 239:487-91.

-.

17. Kurdi-Haidar B, Mason PJ, Berrebi A, Ankra-Badu G, Al-Ali A, Oppenhein A, Luzzatto L. Origin and spread of the glucose-6-phosphate dehydrogenase variant (G6PD-Mediterranean) in the Middle East. Am J Hum Genet 1990; 47:1013-9.

18. Niessner $\mathrm{H}$, Beutler E. Contamination of commercially available intermediates of the glycolytic pathway. Experientia 1973; 29:268-73.

19. Rinaldi A, Filippi G, Siniscalco M. Variability of red cell phenotypes between and within individuals in an unbiased sample of 77 heterozygotes for G6PD deficiency in Sardinia. Am J Hum Genet 1976: 28:496-505.
20. Gall GC, Brewer GJ, Dern RJ. Studies of glucose-6-phosphate dehydrogenase activity of individual erythrocytes: the methemoglobin elution test for identification of females heterozygous for G6PD deficiency. Am J Hum Genet 1965; 17:359368.

21. Van Noorden CJF, Vogels IMC. A sensitive cytochemical staining method for glucose-6-phosphate dehydrogenase activity in individual erythrocytes. Br J Haematol 1985; 60:57-63.

Received November 6, 1995/January 31, 1996

Corresponding author: Dr. Andrea Mosca, Dip. Scienze Tecnol. Biomediche, Via Fratelli Cervi 93, I-20090 Segrate, Milano, Italy 